\title{
Analysis Of Steel-Rec Composite Deck Bridge
}

\author{
A.Sharma*1, K.K. Pathak ${ }^{2}$, Pramod K. Singh ${ }^{3}$ \\ ${ }^{1}$ Research Scholar, Department of Civil Engineering, IITBHU, Varanasi, India (221005) \\ ${ }^{2}$ Professor, Department of Civil Engineering, IITBHU, Varanasi, India \\ ${ }^{3}$ Ex-Professor, Department of Civil Engineering, IITBHU, Varanasi, India
}

Article History: Received:11 January 2021; Accepted: 27 February 2021; Published online: 5 April 2021

Abstract. : In the literature, provisions for analysis and design of steel-RCC composite deck type truss and cablestayed bridges do not exist. A composite deck type truss bridge model is analyzed using STAAD Pro V8i software and a model with the same dimensions is tested in the laboratory. The experimental test results are used to validate the STAAD analysis results.

Bottom chord strain and mid-span deflection of the composite bridge model as found from the STAAD analysis and the laboratory experiment closely tally with each other. This validates the standard STAAD analysis results. However, in the top chord member, due to shrinkage cracks in the deck slab concrete, the experimentally recorded strain is higher by about $100 \%$ than the STAAD analysis result.

Shear force in studs is considerably large near supports and joints as compared to the midsection. Therefore, the design of shear studs may be carried out based on the shear forces in the studs found from the STAAD analysis.

Thus it is recommended that STAAD or any other standard finite element analysis software can be used for analysis and design of the composite bridges.

Keywords: Composite deck bridge; truss bridge; cable-stayed bridge; shear studs; FEM software

\section{INTRODUCTION}

Top chord compression members of a simply supported steel truss bridge may prematurely and suddenly buckle before the material reaches its full compressive strength. In 2012, an open web steel girder non-composite deck bridge of $190 \mathrm{~m}$ total continuous span $(40 \mathrm{~m}+110 \mathrm{~m}+40 \mathrm{~m})$ suddenly collapsed (figure 1$)$ during casting of the deck slab due to buckling of its top chord member U13U14 [1].

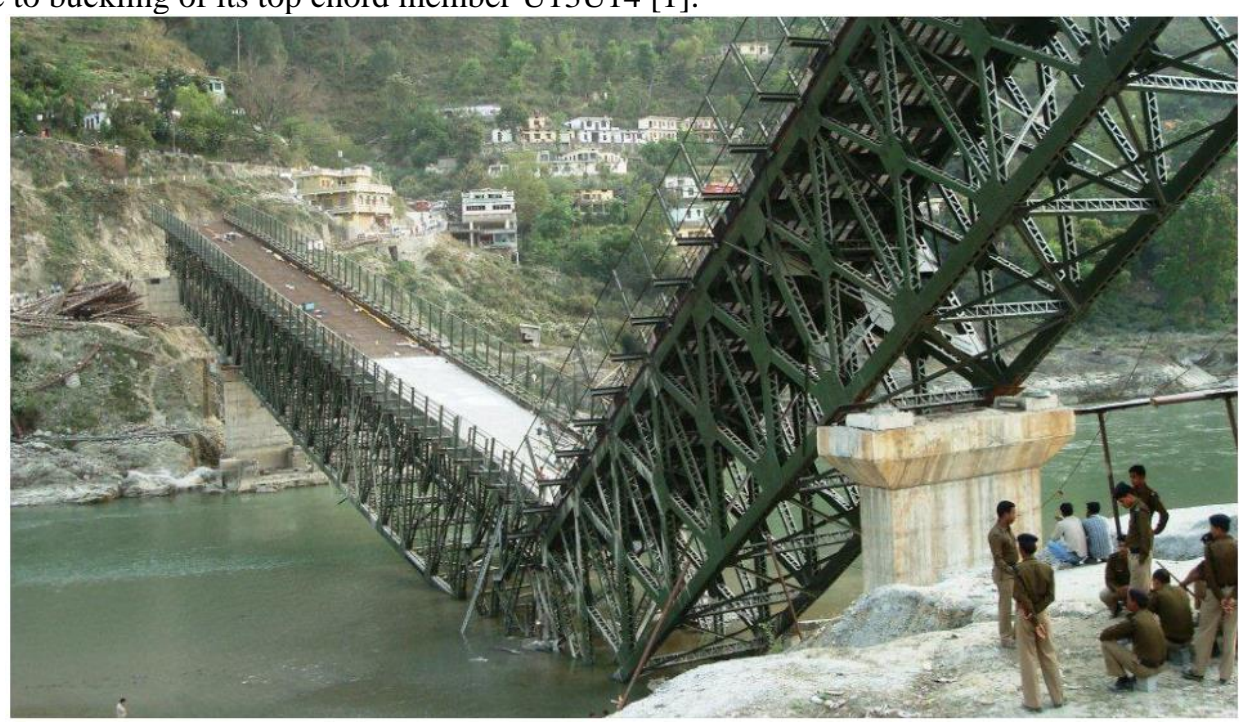

Figure 1: Failed Chauras Bridge

Had the bridge been designed as a composite bridge with shear connectors between the top chord compression members and the RCC deck slab, the sudden failure due to buckling of the top chord member may have been possibly prevented during casting of the deck slab. Also, the failure mode due to buckling of one of its top chord members in an overload condition during service of the bridge would have changed to failure by rupture of its bottom chord member, provided the web members did not fail earlier.

The composite bridges are stronger, stiff and have lower deflection in the service condition. Also, reserve strength beyond the design service load is much higher in the composite bridges. In Czech Republic, twelve simply supported composite steel truss bridges spanning between $21 \mathrm{~m}$ to $63 \mathrm{~m}$ were constructed in the last decade [2]. Composite decks increase lateral stiffness of the structure along with load sharing, which makes them suitable for a number of different types of bridge systems including cable stayed bridges [3].

Finite element modeling and analysis of the composite bridges may be followed for the analysis of composite 
steel truss and cable-stayed bridges, provided results of the analysis are validated. Analysis of a composite bridge model using STAAD Pro V8i [4] FEM software is presented herein, the results of which are validated using findings of the experimental tests. Based on this use of any standard FEM software for modeling and analysis of composite steel truss bridges is recommended.

\section{ANALYSIS OF STEEL-RCC COMPOSITE DECK TRUSS BRIDGE}

A simplified composite deck truss bridge model as shown in figure 2 is selected for modeling and analysis using STAAD Pro V8i software. The same model was tested in the laboratory and the test results are used to validate the analysis results.

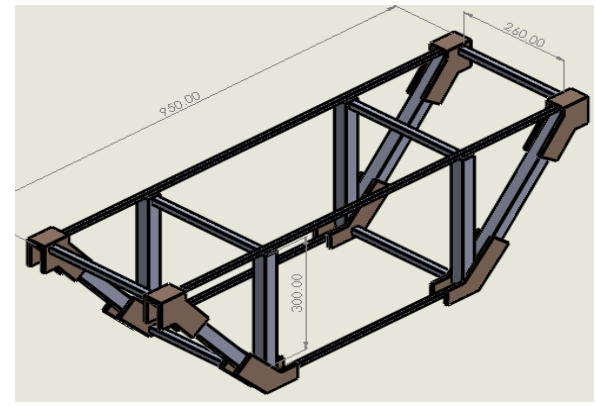

(a) 3-D model

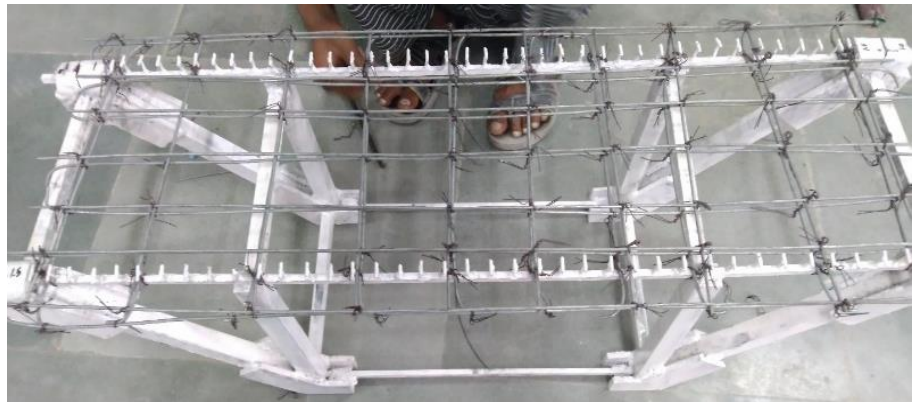

(b) Shear studs and deck reinforcement

Figure 2: Details of the composite bridge model

The structural steel used in the truss model is of E 600 grade having yield stress of $660.0 \mathrm{~N} / \mathrm{mm}^{2}$. At the midspan, the bottom chord tension and the top chord compression are equal. The cross-section of the middle top and bottom chord square bar members is $8.0 \mathrm{~mm}$ x $8.0 \mathrm{~mm}$. Except these, all other members are made stronger, so that failure of the truss is ensured either by buckling of the top chord or by rupture of the bottom chord. Fourpoint loading is applied on the frame and the resulting member forces are shown in figure 3 .

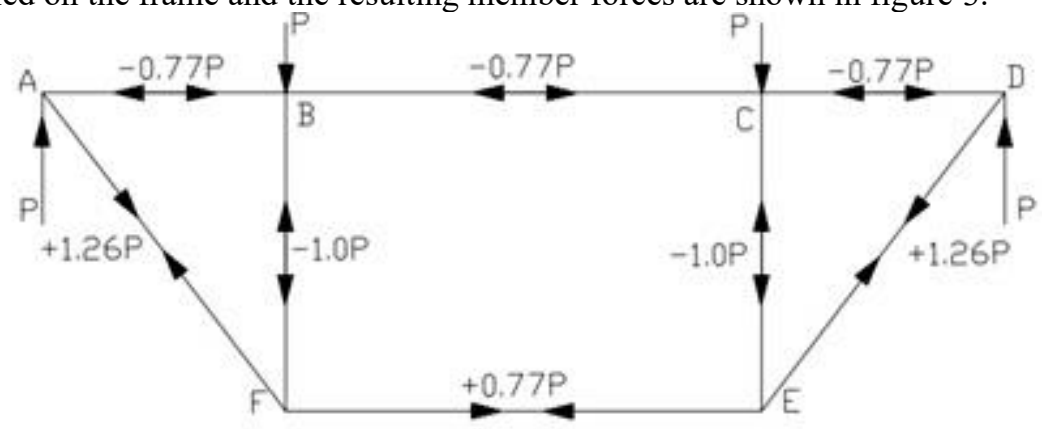

Figure 3 Loading and member forces in the model.

The composite RCC deck slab has 20mm thickness. Shear studs are designed as per IRC 22:2008 [5]. Hammerhead type shear studs of $3.0 \mathrm{~mm}$ diameter and $18.0 \mathrm{~mm}$ height are provided over each top chord member at a spacing of $22.0 \mathrm{~mm} \mathrm{c/c}$ (figure 2.b). Two layers of $3.0 \mathrm{~mm}$ dia. steel wire at a spacing of $60 \mathrm{~mm} \mathrm{c} / \mathrm{c}$ across the deck slab and $100 \mathrm{~mm}$ c/c along the deck is provided as the deck slab reinforcement (figure 2.b).

Vertical deflections in the middle of the bottom chords are recorded using dial gauges. Strains in the bottom chord, top chord and deck slab are recorded using electrical strain gauges.

The composite bridge is modeled on STAAD.Pro V8i software (figure 4). All the steel members are modeled as space frame lineal members, and 4 nodded plate elements are used for modeling the RCC deck slab.

Shear studs of dia. $5.5 \mathrm{~mm}$ at $8 \mathrm{~cm} \mathrm{c} / \mathrm{c}$ are modeled in the STAAD, such that cross-sectional area of the $3 \mathrm{~mm}$ shear studs at $22 \mathrm{~mm} \mathrm{c/c}$ used in the tested model are equal.

\subsection{Meshing of the deck slab}

The following two meshes (figure 4.a and 4.b) are used for the STAAD modeling and the resulting deflections are compared. 

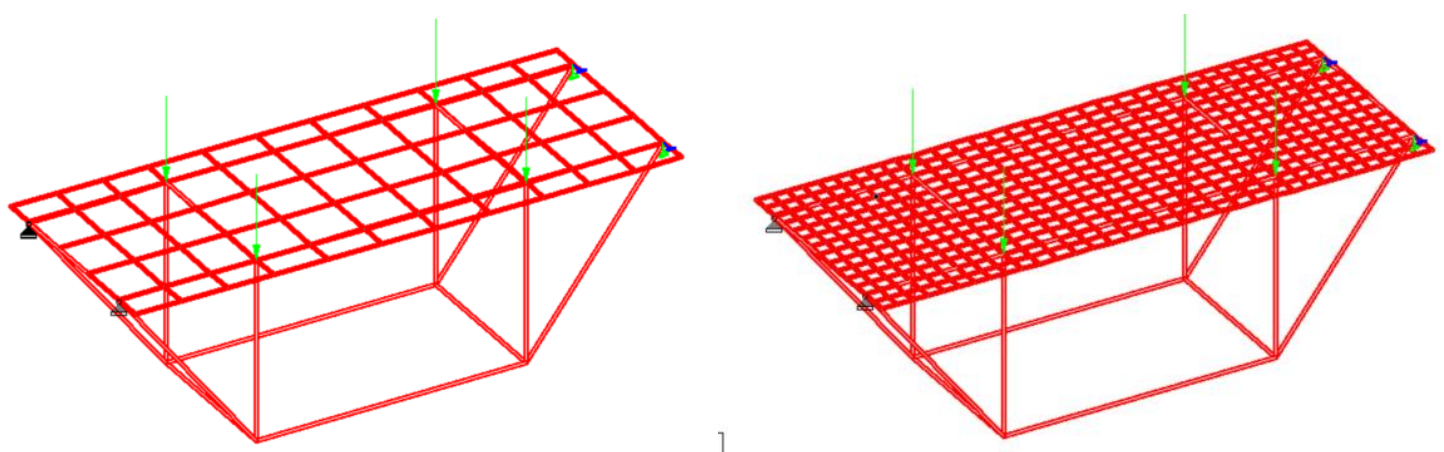

(a) Deck slab modeled with 67 plate elements (b) deck slab modeled with 461 plate elements

Figure 4: Meshing of the deck slab

The deflection of the composite models with the above two meshes of the deck slab is compared in figure 5 .

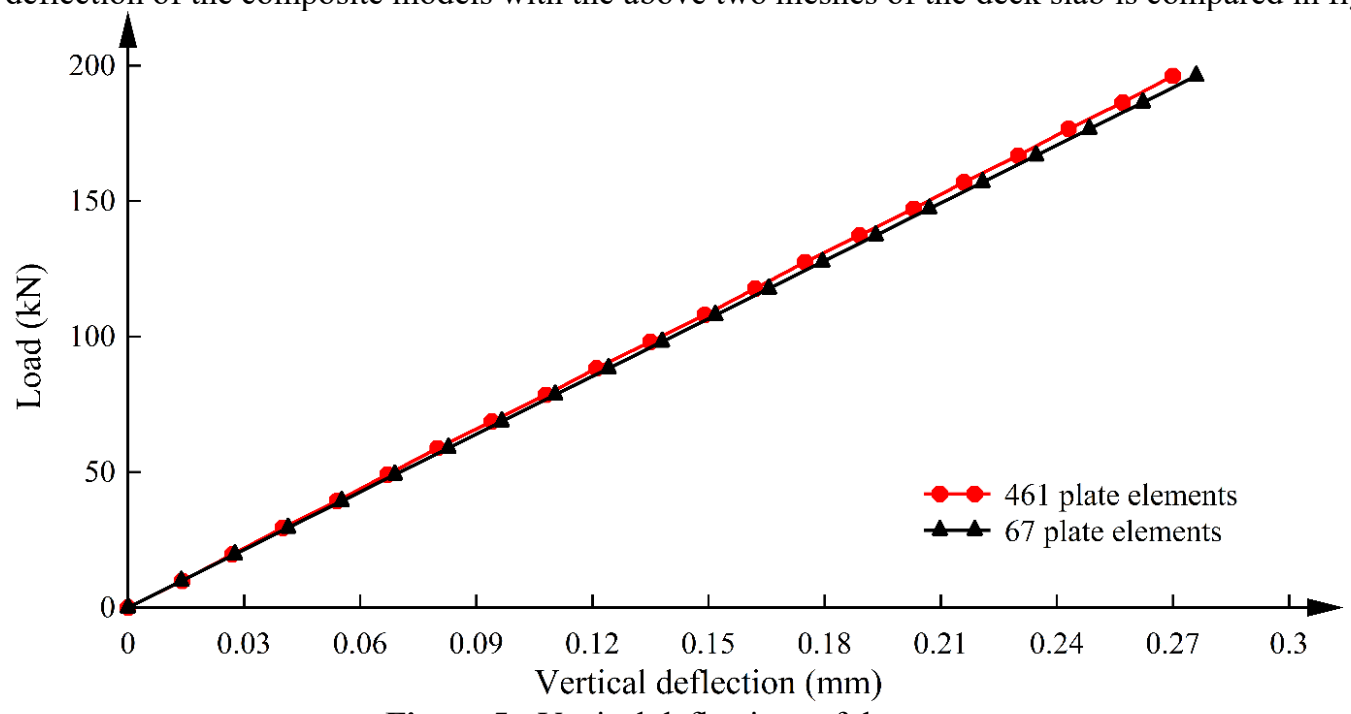

Figure 5: Vertical deflections of the truss

From figure 5 it is clear that the mesh size of the deck slab has little effect on the analysis results provided aspect ratio of the elements is near one. For further discussions deck slab with 461 elements is used.

\subsection{VALIDATION OF THE STAAD RESULTS}

The FEM analysis procedure is widely applicable for analysis of different types of structures, and therefore it is used here to analyze the composite bridge models. To validate the analytical findings using the FEM analysis the following checks are applied.

i. The bottom chord strain is calibrated using the electrical strain gauge results. (Fig.6)

ii. The steel top chord strain is validated using the electrical strain gauge results. (Fig. 7)

iii. The deflection at the mid-span is calibrated using the experimental results. (Fig. 8)

\subsection{Strain in the bottom chord}

The analyzed strains by using the STAAD model and the experimentally recorded strain in the bottom chord and are compared in figure 6. 


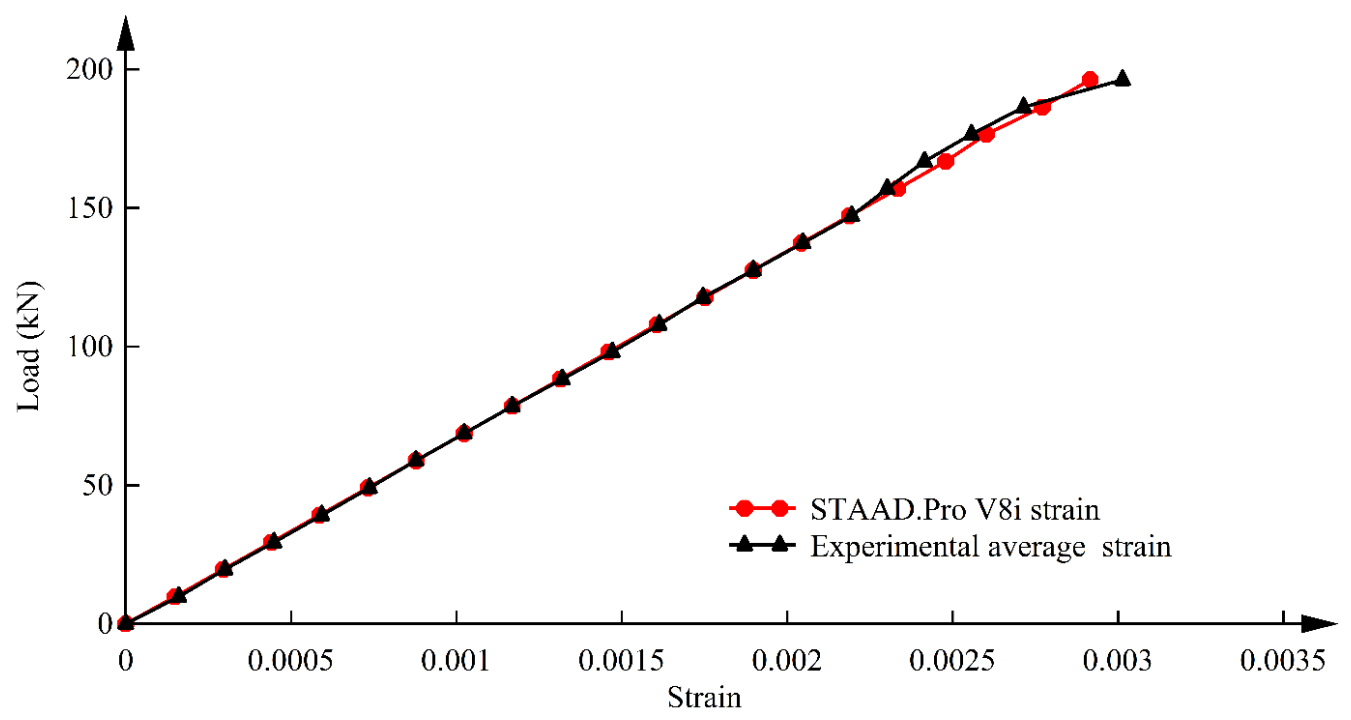

Figure 6: Strain in the bottom chord

Comparison of the strains obtained from the STAAD analysis and the experimentally recorded strain and at various loading stages are seen to closely tally. Thus, the STAAD model results for the bottom chord strain are calibrated.

\subsection{Strain in the top chord}

Total compression in the composite top chord at the mid-span of the truss must be equal to the tension in the bottom chord. Total compression in the top chord comprises compression in the deck concrete, reinforcing steel in the deck, and the steel top chord. At any stage of loading, compressive forces in the three components of the top chord are suitably adjusted to keep the total compressive force equal to the tensile force in the bottom chord.

Strain variation in the steel top chord members, as found from the STAAD analysis and experimentally measured, is shown in figure 7.

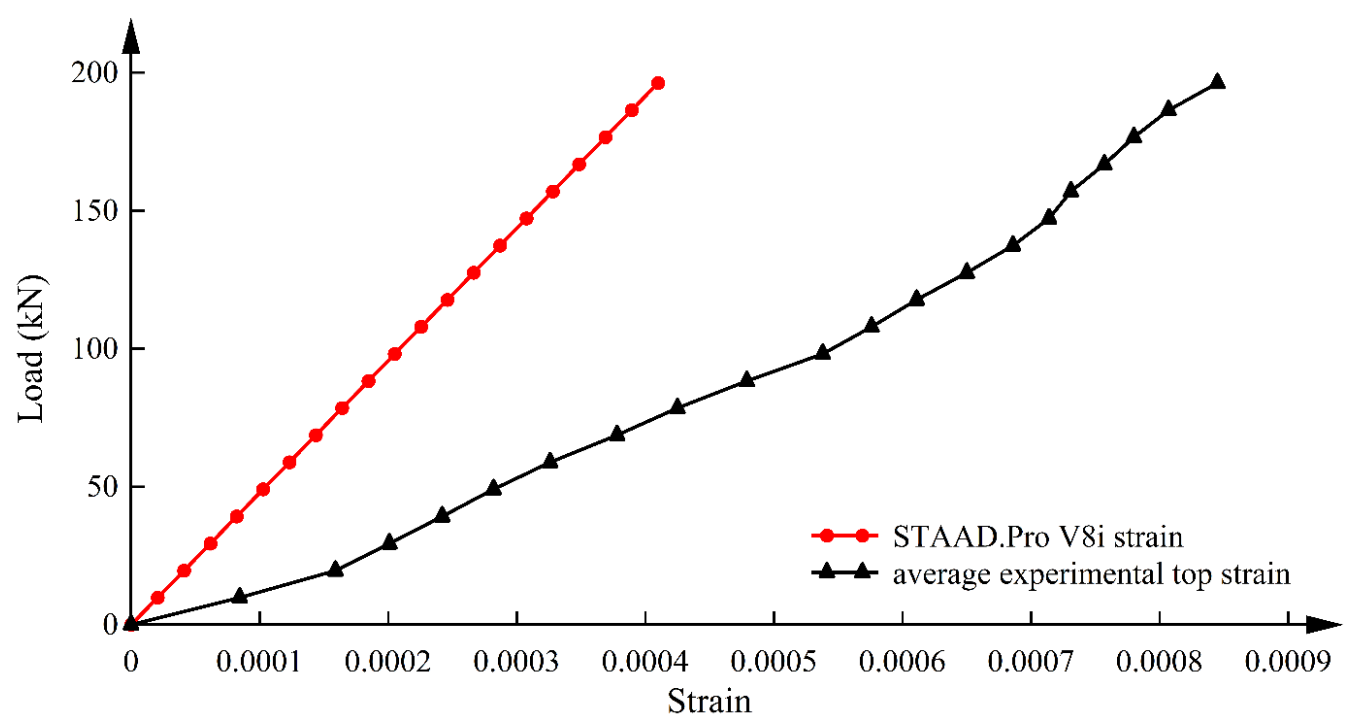

Figure 7: Strain in the steel top chord

The experimentally recorded strain is higher by about $100 \%$ than the STAAD analysis strains. This is due to shrinkage cracks present in the deck slab. Therefore, in the composite sections, computed force in the steel section may be doubled for design purposes.

\subsection{Deflection at mid-span}

Experimental and analytical deflections of the bridge model at the mid-span of the model are shown in figure 8 . 


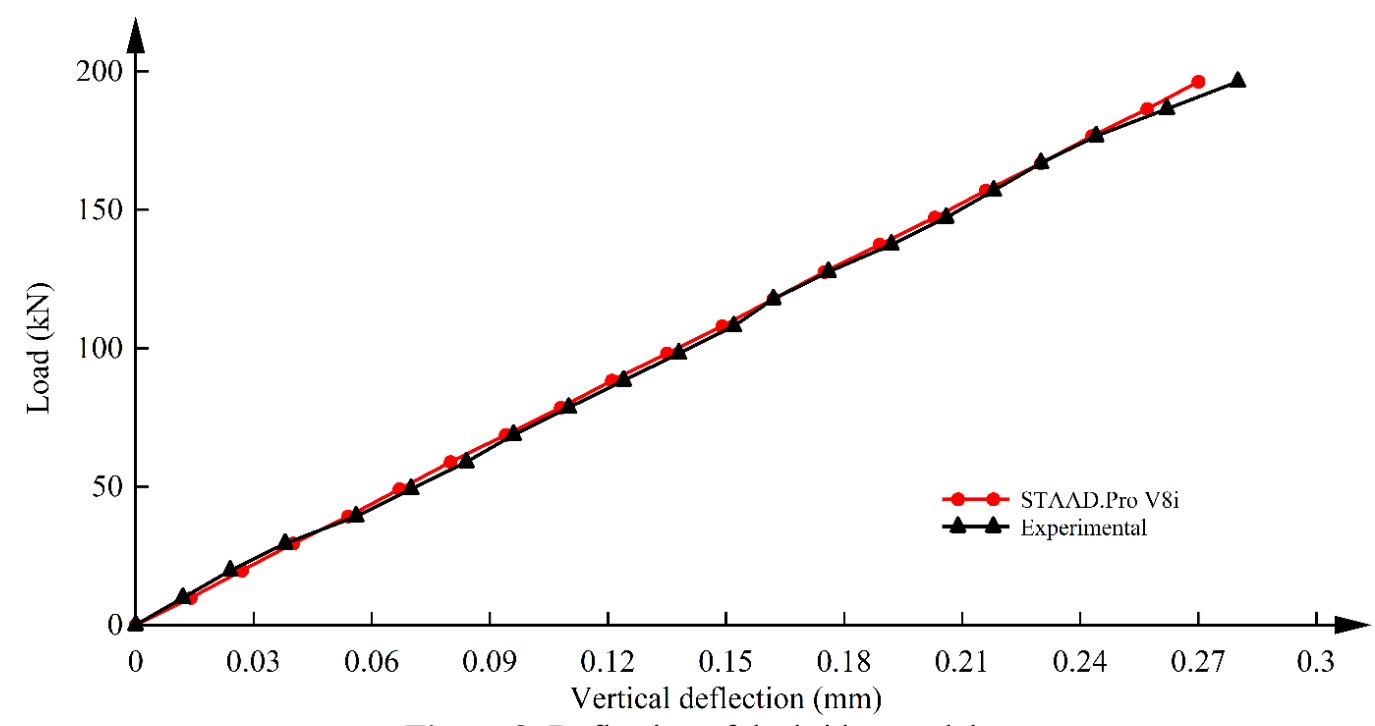

Figure 8: Deflection of the bridge model.

The bridge model failed at $196.2 \mathrm{kN}$ at a deflection of $0.28 \mathrm{~mm}$. Experimental deflection in figure 8 is seen to closely tally with the linear STAAD model result. Therefore, deflection found from the STAAD model analysis is calibrated.

\subsection{Strain in the deck slab}

In the experiment, five strain gauges were fixed at top of the deck slab along the width of the model at the center span. The plot of the strains recorded at various loading stages is shown in figure 9 in firm lines. Strains obtained for the STAAD analysis are shown in dotted lines.

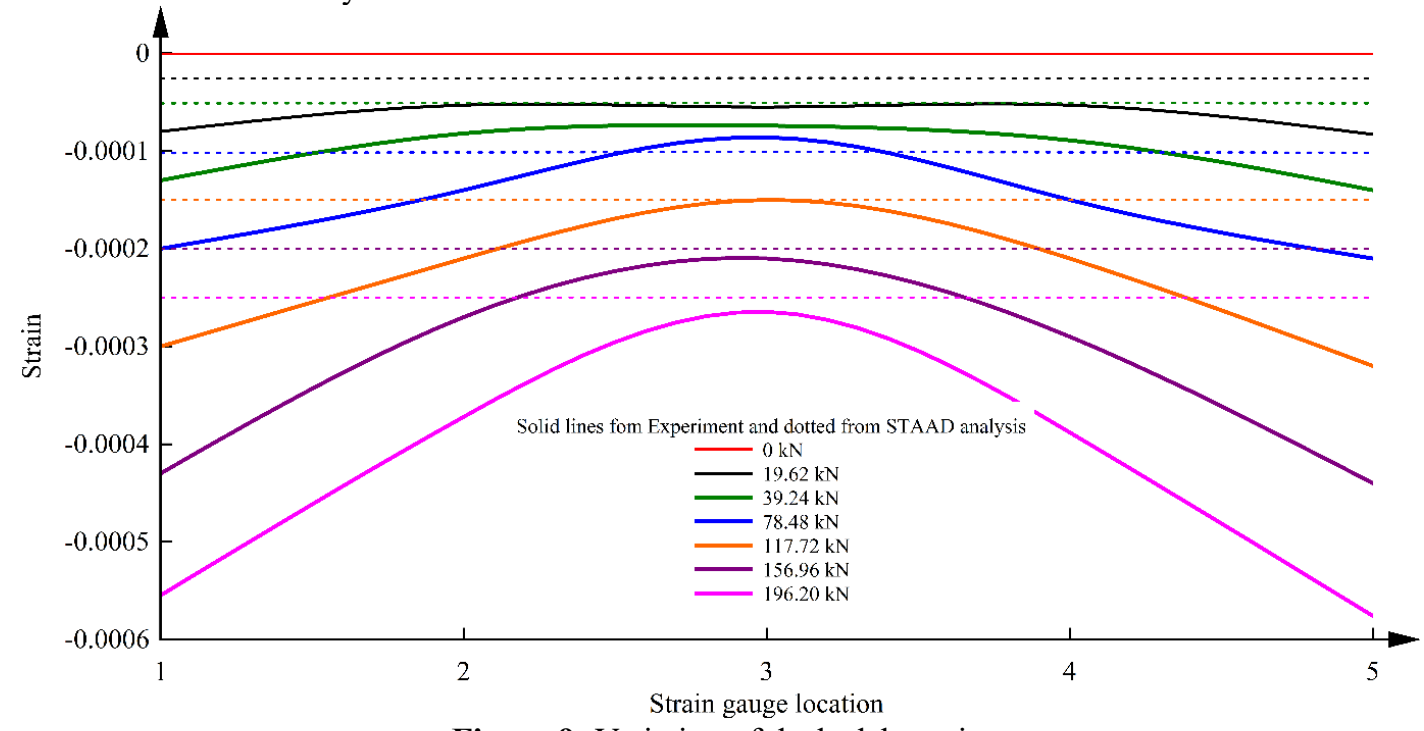

Figure 9: Variation of deck slab strain

Experimentally recorded strains are seen to vary along the width of the slab with maximum strain at the truss locations. The average strain in the deck slab at the failure load of $196.2 \mathrm{kN}$ is 0.72 times the maximum strain.

\subsection{DESIGN OF SHEAR STUDS AS PER STAAD MODEL}

Load sharing between the steel top chord member and the RCC deck as found in the experiment is $28.0 \%$ in the top chord and $72.0 \%$ in the RCC deck (Figure 10). 


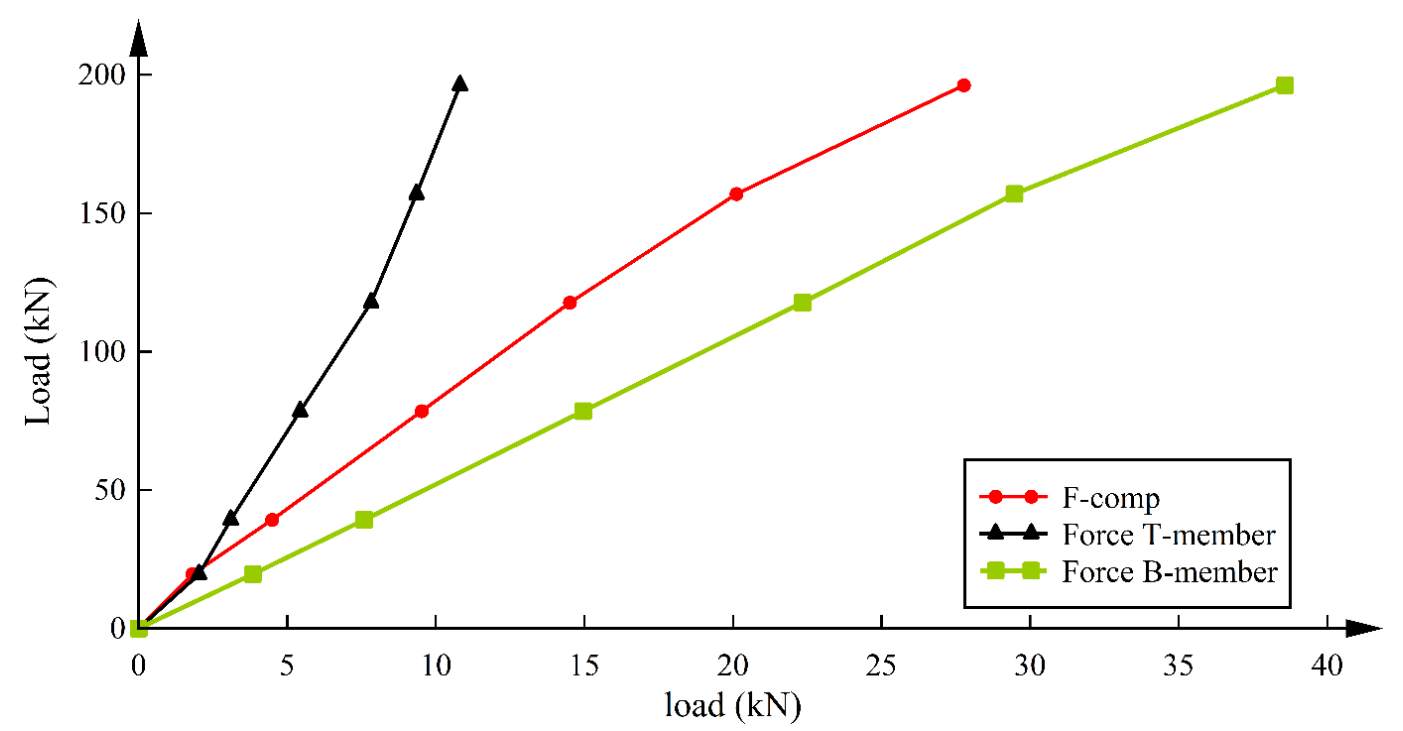

Figure 10: Load sharing between top chord, bottom chord, and concrete deck

Shear transfer between the steel top chord and RCC deck in the elastic range is an important phenomenon. Failure of a composite truss bridge takes place by rupture of the bottom chord, and therefore, plastic redistribution of shear forces in rigid shear studs is not applicable in the case of composite truss bridges.

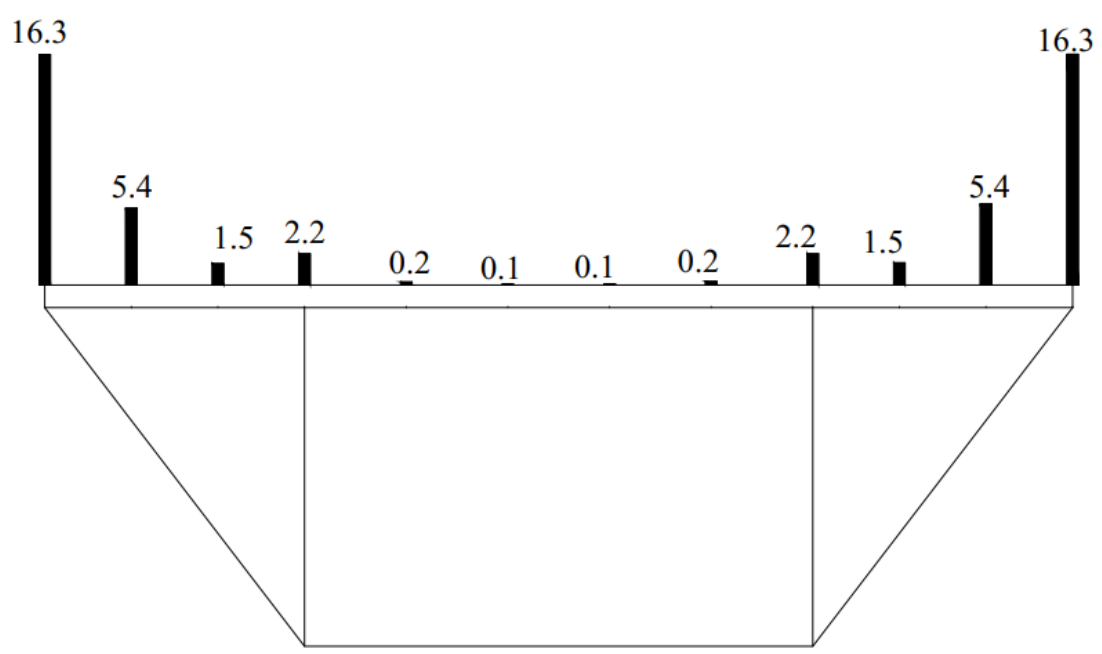

Figure 11: Variation of shear force $(\mathrm{kN})$ in studs as per STAAD

Figure 11 shows the variation of the shear force in shear studs in the STAAD analysis. It is seen that the force is considerably large near supports and joints as compared to the midsection.

As the STAAD model is validated, the design of shear studs may be carried out based on the shear forces in the studs found from the STAAD analysis.

\subsection{ADVANTAGES OF THE COMPOSITE ANALYSIS IN BRIDGE DESIGN}

The following three examples of steel truss and cable-stayed bridges are presented to highlight the applicability and advantages in bridge design.

\subsection{Through type composite bridge example}

A 72.0 m composite bridge, where the deck slab is composite with the cross girders and the bottom chords of the truss, is taken for the analysis and the results are compared with the non-composite bridge model. 


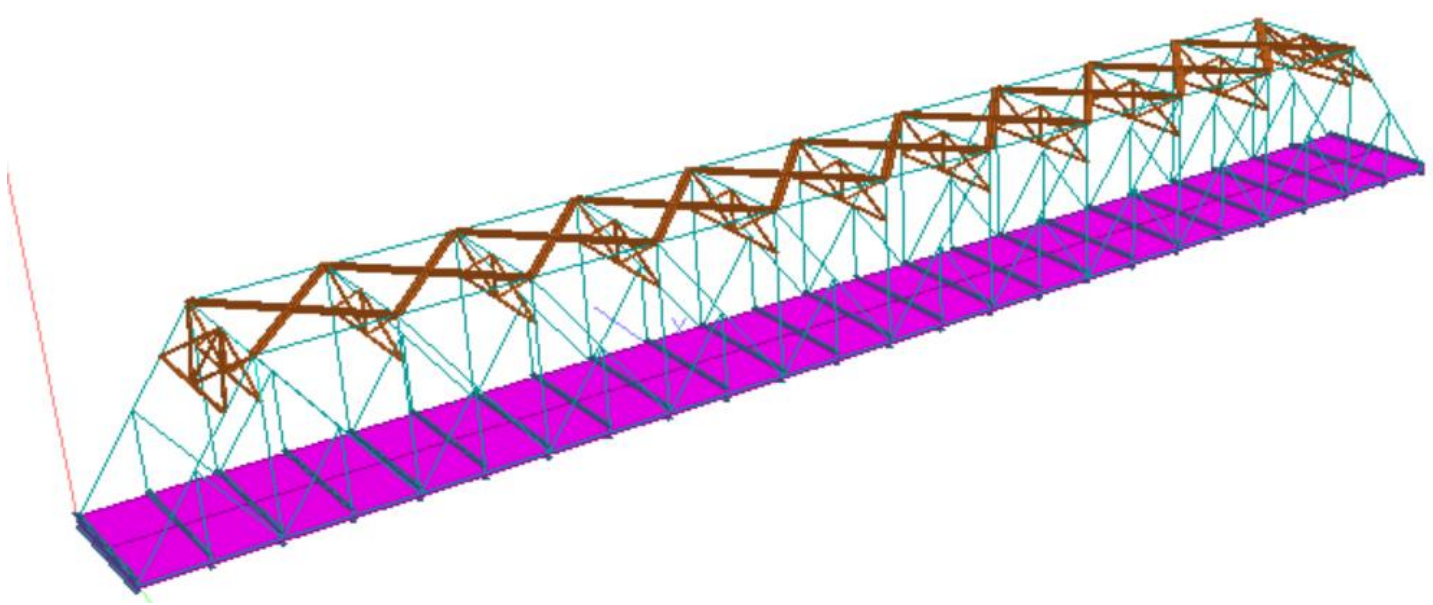

Figure 12: 3-D STAAD composite bridge model.

A comparison of the deflections and member stresses for the non-composite deck and composite deck bridges is given in table 1 .

Table 1: Comparison of Non-composite and composite $72 \mathrm{~m}$ bridges.

\begin{tabular}{|l|l|l|l|}
\hline S.No. & Item & $\begin{array}{l}\text { Non-composite } \\
\text { bridge }\end{array}$ & $\begin{array}{l}\text { Composite } \\
\text { bridge }\end{array}$ \\
\hline \multicolumn{3}{|l|}{ Maximum bridge deflection (mm): } & \\
\hline 1 & $\begin{array}{l}\text { Vertical deflections } \\
\text { due to DL }\end{array}$ & 99.6 & 77.9 \\
\hline 2 & Vertical deflection due to LL & 71.6 & 51.3 \\
\hline 3 & Horizontal deflection due to Wind Load & 133.0 & 10.4 \\
\hline 4 & Horizontal deflection due to Seismic load & 186.7 & 8.9 \\
\hline \multicolumn{3}{|l|}{ Maximum DL+LL member stresses $\left(\mathbf{N} / \mathbf{m m}^{\mathbf{2}}\right) \mathbf{~}$} & 174.4 \\
\hline 5 & Top chord & 177.6 & 165.2 \\
\hline 6 & Bottom chord & 97.8 & 55.1 \\
\hline 7 & Web vertical members & 115.1 & 86.2 \\
\hline 8 & Web inclined members & 160.4 & 123.7 \\
\hline 9 & Bottom cross girder & 95.2 \\
\hline
\end{tabular}

From table 1, the following conclusions can be drawn

i. The vertical deflection of the composite bridge under various loading conditions is quite small in comparison to the non-composite bridge.

ii. Due to the rigidity of the deck slab in the horizontal plane, the horizontal displacement of the bridge nearly vanishes in the composite bridge case.

iii. Stresses in various members of the composite bridge are quite small in comparison to the con-composite bridge stresses. Especially, in the bottom chord, the maximum stress decreases to about $31 \%$ in the composite bridge case. Similarly, for the bottom cross girder, the maximum stress reduces to about $60 \%$ in the composite bridge case.

Thus the composite bridge analysis is essential in this case.

\subsection{Semi deck type composite bridge model.}

A 72.0m span semi deck type bridge, supported at mid-height at the ends, is shown in figure 13. 


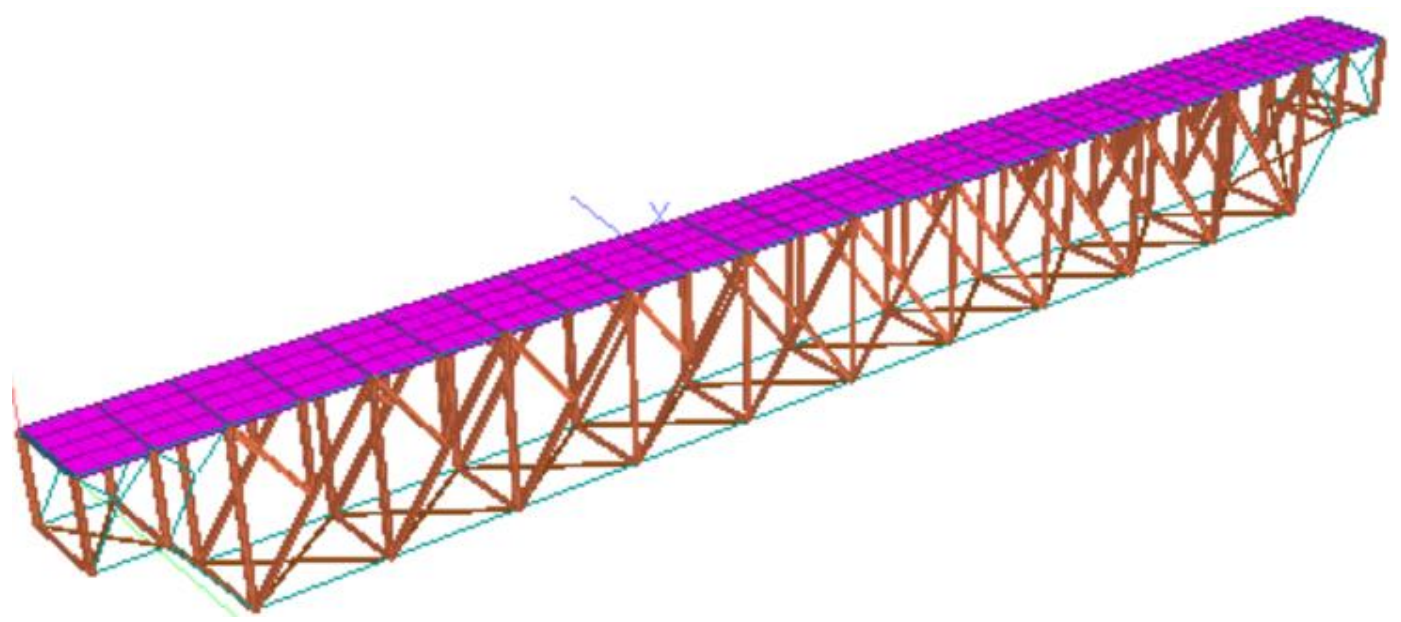

Figure 13: Semi deck type composite bridge.

In this example, the composite deck is placed at top of the truss, and it effectively prevents buckling of the steel top chord members in addition to sharing a major portion of the truss compressive force. The composite analysis results in a stiffer and stronger bridge in comparison to the non-composite bridge analysis.

\subsection{Composite deck cable-stayed bridge}

Cable-stayed bridge longitudinal girders are prone to buckling due to high axial forces caused by the cable tensions [6]. Composite deck in a cable-stayed bridge prevents buckling of the steel longitudinal girders. Analysis of cable-stayed bridge with composite decks can be carried out similarly as explained for the composite steel truss bridge cases above. M.F.Granata et.al. [7] have presented construction stages of cable-stayed bridges with composite decks, where FEM analysis has been used for modeling the bridge deck. Analysis for horizontal and longitudinal stiffnesses of composite deck cable-stayed bridges can be carried out in a similar way as for the composite truss bridges, which may lead to significant increase in strength and vertical and horizontal stifnesses of the bridge.

\section{CONCLUSIONS}

Comparing the STAAD analysis results with the experimental results, it is attempted to calibrate the STAAD model so that the validity of the STAAD model results for the analysis of the composite bridges is upheld. From the presentation, the following detailed conclusions are drawn.

i. In the STAAD model, the mesh size of the deck slab has little effect on the analysis results provided aspect ratio of the elements is near one.

ii. The bridge model failed at $196.2 \mathrm{kN}$ at a deflection of $0.28 \mathrm{~mm}$. The experimental result closely tallies with the STAAD model result in which the deflection at the failure load is $0.27 \mathrm{~mm}$.

iii. Strain in the steel bottom chord of a composite truss bridge, obtained from the STAAD analysis and the experimentally recorded strain closely tally. Thus, the STAAD model results for the bottom chord strain are calibrated.

iv. In the top chord member, due to shrinkage cracks in the deck slab concrete, the experimentally recorded strain is higher by about $100 \%$ than the STAAD analysis result. Therefore, while designing the composite section force in the steel component obtained from the STAAD analysis have to be doubled for design.

v. Strain in the deck slab varies in the transverse direction with maximum strain at the truss locations. The average strain in the deck slab at the failure load of $196.2 \mathrm{kN}$ is 0.72 times the maximum strain.

vi. It is recommended that shear force in the shear studs, as analyzed by the STAAD model, may be taken as the basis for the design of the shear studs.

vii. Analysis of composite steel truss and cable-stayed bridges results in highly stiff and strong bridge design, and therefore the FEM analysis for steel-RCC composite deck type bridges is strongly recommended.

viii. Shear force in studs is considerably large near supports and joints as compared to the midsection. Therefore, the design of shear studs may be carried out based on the shear forces in the studs found from the STAAD analysis.

STAAD analysis results for steel-RCC composite deck type steel truss and cable-stayed bridges are calibrated using the experimental results. It is found that STAAD satisfactorily analysis the composite steel truss bridge for its bottom chord strains and the bridge deflection. It is recommended that the analysis and design of a steel-RCC composite deck type bridges may be carried out using STAAD.Pro V8i or any standard FEM analysis package. 


\section{REFERENCES}

[1] H. S. Birajdar, P. R. Maiti, P. K. Singh. "Failure of Chauras bridge." Engineering Failure Analysis, Elsevier, Vol. 45, 2014, pp. 339-346.

[2] J. Machacek, M. Charvat. Design of Shear Connection between Steel Truss and Concrete Slab, 11th International Conference on Modern Building Materials, Structures and Techniques, MBMST 2013, Procedia Engineering, Elsevier, 57, pp. 722-729, 2013.

DOI:10.1016/ j.proeng.2013.04.091.

[3] J.B.Marcussen. Design and construction in composite bridges", EUROSTEEL 2017, September 13-15, 2017, Copenhagen, Denmark.

[4] STAAD.Pro V8i Technical reference manual, Bentley.

[5] IRC: 22-2008, "Standard Specifications and Code of Practice for Road Bridges Section VI (Composite Construction)," Indian Road Congress, 1986, India.

[6] Hung-Shan Shu, and Yang-Cheng Wang, "Stability analysis of box-girder cable-stayed bridges," Journal of bridge engineering, 2001, pp. 63-68.

[7] M.F. Granata, P. Margiotta, M. Arici, A. Recupero, "Construction stages of cable-stayed bridges with composite deck", Bridge structures 8, 2012, 93-106. 